Peer-Reviewed Article

ISSN: 2162-3104 Print/ ISSN: 2166-3750 Online

Volume 7 Number 1 (2017), pp. 38-52

(C) Journal of International Students

http://jistudents.org/

\title{
Are International Students Quiet in Class? The Influence of Teacher Confirmation on Classroom Apprehension and Willingness to Talk in Class
}

\author{
Chia-Fang (Sandy) Hsu \\ University of Wyoming, USA \\ I-Ting (Joyce) Huang \\ Synnix Industries Inc., Taiwan
}

\begin{abstract}
This study investigated the influence of teacher confirmation (TC) on classroom apprehension (CCA) and willingness to talk in class (WTT) among international students in the United States. The participants $(N=121)$ completed a battery of self-report instruments online. Results confirmed a path model that TC positively predicts classroom connectedness, which in turn, positively influences self-perceived language competence, which subsequently reduces CCA and increases WTT. The influences of length of stay in the U.S. and class size were controlled in the model, while culture of origin and class type did not influence CCA and WTT. Implications of these findings were further discussed.
\end{abstract}

Keywords: teacher confirmation, classroom connectedness, classroom apprehension, willingness to talk, language competence, international students

There were 4.3 million international students worldwide in 2011, and the number was projected to reach 8 million in 2025 (Organisation for Economic Co-operation and Development [OECD], 2013). The United States hosted more international students than any other country, and the enrollment rose steadily with an $8.1 \%$ growth in 2013/14 to a record high of 886,052 international students (Institute of International Education, 2014).

Although studying abroad has become a trend, the majority of faculty (77\%) in the College of Business at two southeastern universities 
reported that class participation is the top issue among international students in the U.S. (Tompson \& Tompson, 1996). Most international students in the U.S. (82\%) are from non-English-speaking nations (OECD, 2014). Many international students attributed their difficulty to fear or anxiety associated with speaking in English (Liu, 2007; Lu \& Hsu, 2008). The differences in the cultural values and school environments might also explain why international students experience communication anxiety during class discussion. For example, the collectivistic cultural orientation, which emphasizes group harmony, may make Asian students more hesitant to assert themselves in a meeting than American students with individualistic cultural values that presume the uniqueness of individuals (Hsu, 2007). The teacher-centered and authoritarian teaching style in Asian countries also encourages students to be quiet in the classroom (Hsu, 2002; Myers, Zhong, \& Guan, 1998; Zhang, 2005).

Given that class participation results in better grades and learning outcomes in American colleges and universities (Sidelinger \& BoothButterfield, 2010), it is important to illuminate how teachers can help international students overcome communication anxiety and improve class participation. Although previous studies (Tompson \& Tompson, 1996; Liu, 2007) have recommended strategies, such as improving students' language skills, little research has investigated instructional practices and classroom environment that can facilitate class participation among international students. According to Sidelinger and Booth-Butterfield (2010), both teacher-student and student-student relationships are important to student involvement in and out of class. Teacher confirmation behaviors, which emphasize teachers' relating behaviors with students, have been found to reduce students' listening apprehension and improve learning outcomes (Ellis, 2004; Hsu 2012). Classroom connectedness, which refers to a cooperative and supportive climate among students (Dwyer, Bingham, Carlson, Prisbell, Cruz, \& Fus, 2004), is another significant factor contributing to student involvement (Sidelinger \& Booth-Butterfield, 2010). Furthermore, research (Clément, Baker, \& MacIntyre, 2003) on second language (L2) learning indicated that a positive intergroup climate improves students' communicative confidence in L2, which in turn increases their desire to communicate with the L2 group. Teachers' confirmation behaviors and supportive classroom climate should help international students participate in American classroom. However, research has not investigated these possibilities. Therefore, the purpose of this study was to examine whether teacher confirmation and classroom connectedness could increase self-perceived language competence, which in turn reduces classroom apprehension and increases willingness to talk in class among international students in the U.S. 


\section{LITERATURE REVIEW}

\section{Classroom Apprehension and Willingness to Talk in Class}

McCroskey (1977) originally defined Communication apprehension as fear or anxiety associated with either real or anticipated communication with other people. Neer (1987) studied apprehension experienced in the classroom setting and defined classroom apprehension (CCA) as evaluation apprehension or expectation of negative outcomes associated with class participation. Students felt more comfortable in discussion when they perceived the class as a less formal, more familiar and more accepting environment (Neer \& Kircher, 1989).

Willingness to communicate (WTC) refers to the probability of initiating communication with others when the opportunity arises (McCroskey \& Richmond, 1987). Menzel and Carrell (1999) studied willingness to talk in class focusing on students' likelihood to talk in class in several situations: interest in class or topic, motivation, similarity to the rest of the students, similarity to the instructors, and seating arrangement. MacIntyre, Clément, Dörnyei, and Noels (1998) further developed a theoretical model to explain WTC in a second language. The model follows hierarchical layers of variables. The first layer of variables are communicative self-confidence and desire to communicate in a specific situation. The second layer of variables are interpersonal motivation, intergroup motivation, and L2 self-confidence. The final layers, which include intergroup attitudes, communicative competence, intergroup climate and personality traits, represent enduring influences on the process. Based on this WTC model, enduring influences are presumed to influence L2 selfconfidence, self-perceived communication competence, and motivational propensities, which in turn influence desire to communicate, WTC, and other communication behaviors in L2. Thus, international students may be less apprehensive and more willing to communicate in class when they experience positive intergroup climate and attitudes, and feel confident about communicating in L2.

\section{The Influence of Teacher Confirmation on CCA and WTT}

Ellis (2000) defined teacher confirmation (TC) as "the transactional processes by which teachers communicate to students that they are endorsed, recognized, and acknowledged as valuable, significant individuals" (p. 266). Teacher confirmation consisted of three elements: (a) teachers' responses to students' questions and comments, (b) interest in students or their learning, and (c) an interactive teaching style (Ellis, 2000). Teacher confirmation behaviors have been found to reduce students' fear of not being able to comprehend class material, and improve students' 
perceived learning (Ellis 2004; Hsu, 2012) and class involvement (Sidelinger \& Booth-Butterfield, 2010). When a teacher shows interest in students by using praise, smiles, and eye contact, students will feel more encouraged expressing their thoughts in class. When a teacher communicates messages that support and confirm international students' learning effort, students will feel valued and confident in class, which in turn they may experience less fear in participation and are more likely to initiate communication in class. Thus, the following hypotheses were derived (see Figure 1):

H1: Teacher confirmation is negatively related to classroom apprehension. H2: Teacher confirmation is positively related to willingness to talk in class.

\section{The Mediating Role of Classroom Connectedness and Language Competence}

Classroom connectedness (CC) refers to "student-to-student perception of a supportive and cooperative communication environment in the classroom” (Dwyer et al, 2004, p. 269). The relationships between teacher confirmation, classroom apprehension and willingness to talk in class among international students may depend on student-to-student relationships in class. Students in courses with high participation perceived having more supportive and cooperative relationships with fellow students than those in courses with low participation (Fassinger, 2000; Neer \& Kircher, 1989). Similarly, Frisby and Martin (2010) found that good student-to-student relationships facilitate class participation. It can be expected that international students would experience less anxiety in discussion when they feel welcome and accepted by their peers. Thus, the following hypotheses were derived (see Figure 1):

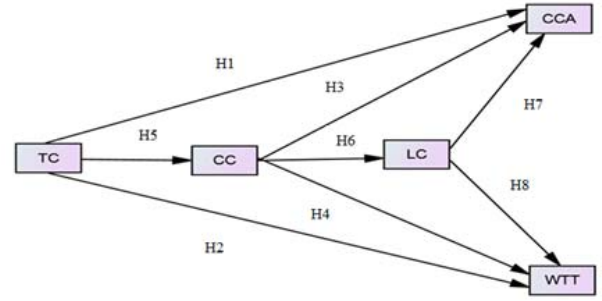

Figure 1.

The hypothetical model of the relationships between Teacher Confirmation (TC), Classroom Connectedness (CC), Language Competence (LC), Classroom Apprehension (CCA), and Willingness to Talk (WTT) in Class

H3: Classroom connectedness is negatively related to classroom apprehension.

H4: Classroom connectedness is positively related to willingness to talk in class. 
Furthermore, classroom connectedness has been found to mediate the relationship between teacher confirmation and student involvement (Sidelinger \& Booth-Butterfield, 2010). Teacher confirmation behaviors not only build up a supportive teacher-student relationship, but also facilitated a participatory learning environment in class. That is, teachers' confirming behaviors help improve student-to-student relationships, which in turn make students more comfortable participating in class. Thus, the following hypothesis was derived (see Figure 1):

H5:Teacher confirmation is positively related to classroom connectedness.

Another factor that may influence the relationships from teacher confirmation and classroom connectedness to CCA and WTT is selfperceived language competence (LC) among international students. LC refers to one's perceptions of his or her own ability of communicating in English in this study. According to MacIntyre et al. (1998), one's degree of L2 proficiency has a significant effect on WTC in L2. Most international students do not speak English as their first language. Because people tend to pay extra attention on a foreign accent and other differences, international students may become very sensitive to others' evaluations and doubt their own ability to communicate clearly; as a result, they may feel uncomfortable when speaking up in class.

In addition, research on WTC theory in L2 indicated that a positive intergroup climate and quality of contact with the $\mathrm{L} 2$ group lead to greater L2 communication confidence (Clément, Baker, \& MacIntyre, 2003). That is, a supportive communication climate in the classroom should make international students feel more confident speaking in L2, and less fearful asserting their points of view in class. Thus, the following hypotheses were derived (see Figure 1):

H6: Classroom connectedness is positively related to self-perceived language competence.

H7: Self-perceived language competence is negatively related to classroom apprehension.

H8: Self-perceived language competence is positively related to willingness to talk in class.

In sum, this study integrated the teacher confirmation model of learning and WTC theory in L2 to explain international students' classroom apprehension and willingness to talk in class in the U.S. Teacher confirmation influences student involvement through building a participatory learning environment in class (Sidelinger \& Booth-Butterfield, 2010). WTC theory (MacIntyre et al., 1998) argued that intergroup climate 
influences communicative self-confidence, which in turn, influences desire to communicate, WTC and other communication behaviors in L2. As applied to the classroom setting, both teacher confirmation and classroom connectedness contribute to intergroup climate between the teacher, domestic and international students, while communicative self-confidence is indicated by self-perceived ability in speaking English. Thus, this study proposed a hypothetical model that teacher confirmation predicts classroom connectedness, which in turn, influences students' language confidence, which subsequently influences students' classroom apprehension and willingness to talk in class (see Figure 1). In addition, the hypothetical model included several control variables, including culture of origin, length of stay in America, class size and class type. Previous research (e.g., Lu \& Hsu, 2008) suggested that these variables might also influence willingness to communicate among international students.

\section{RESEARCH METHOD}

\section{Participants and Procedure}

One hundred and twenty-one $(N=121)$ international students voluntarily completed the questionnaire online at a small-size western university in the United States. The link to the online questionnaire was distributed to international students' school email addresses via the International Student and Scholar Office. The university enrolled approximately 600 international students. The sample size is large enough for detecting significance given the population size (Krejcie \& Morgan, 1970).

The participants' average age was 26 years $(S D=5.84)$, ranging from 18 to 45 years. Of the participants, $46.3 \%$ were men and $51.2 \%$ were women. Eighty-one percent of the participants did not use English as an official language in their native country. The average time of staying in the United States was 21 months $(S D=23.61)$. The participants came from 36 countries (two participants did not clarify their nationality, but identified themselves as Asian and African). The 10 largest groups were as follows: 20.66\% from China, $7.44 \%$ from India, $4.96 \%$ from Nepal, $4.13 \%$ from Canada and Iran, and $1.65 \%$ from Saudi Arabia, South Korea, Sri Lanka, and Vietnam. The demographic characteristics resemble the population of international students in the university mostly.

Participants consisted of 55 different majors across six colleges of the university (all colleges except the college of law). In order to include various types of courses, at the beginning of the questionnaire, participants were asked to identify one class that they just attended right before they filled out this survey. The subjects of the courses they chose to evaluate 
varied from basic required courses (such as political science) to graduatelevel courses. The average class size was 34.93 students. As for class type, $38.8 \%$ of the chosen courses were a discussion-oriented class and $56.2 \%$ of the chosen courses were a lecture-oriented class. Furthermore, $9.9 \%$ of respondents were freshmen, $9.1 \%$ of respondents were sophomore, $9.1 \%$ of respondents were juniors, $7.44 \%$ of respondents were seniors, $26.45 \%$ of respondents were master's students, $30.6 \%$ of respondents were doctoral students, $7.44 \%$ of respondents were exchange students, and $5.8 \%$ of respondents were transfers (participants were asked to check all applied options).

\section{Instruments}

Teacher Confirmation. Teacher confirmation was measured using Ellis' (2000) Teacher Confirmation Scale (TCS). The TCS consists of 16 items and measures behaviors across three dimensions: (a) teachers' responses to students' questions or comments, (b) demonstrated interest in students and in their learning, and (c) teaching styles. Participants evaluated the instructor's confirming behaviors on a five-point Likert scale ranging from "strongly agree" to "strongly disagree." Sample items include "this instructor takes time to answer students' questions fully," and "this instructor makes an effort to get to know students." The scale had good reliability with alpha coefficients ranging from .85 to .95 , and its construct validity was demonstrated in several studies (e.g., Ellis, 2004; Hsu, 2012). Cronbach's alpha reliability was .93 in this study.

Classroom Connectedness. The Connected Classroom Climate Inventory (CCCI), developed by Dwyer et al. (2004), was used to measure students' connectedness with their classmates. The CCCI is an 18-item Likert-type scale with one dimension. Participants evaluated their classroom connectedness from "strongly agree" to "strongly disagree." Sample items include "the students in my class are friendly with one another," and "I feel a strong bond with my classmates." The scale had high alpha reliability of .94 and construct validity (Sidelinger \& Booth-Butterfield, 2010). The reliability in this study was .96.

Classroom Apprehension. The Class Apprehension about Participation Scale (CAPS), developed by Neer (1987), was used to measure the degree of classroom participation apprehension among students during classes. This study adopted the 20-item, 5-point Likert scale with response categories ranging from "strongly agree" to "strongly disagree." Ten items of the scale measure the dimension of communication participation defined as "predisposition to communicate during class discussion" (Neer, 1987, p.157), and the other 10 items measure the dimension of communication confidence referring to "general nervousness or fear of being evaluated by others during discussion" (p. 157). Sample items include "I worry that 
instructor will call on me during class," and "I usually do not speak in class unless called on by the instructor." The scale had high alpha reliability of .94 and construct validity (Neer \& Kircher, 1989). The current reliability in this study was .95 .

Willingness to Talk in Class. Willingness to Talk in Class Scale (Menzel \& Carrell, 1999) was used to measure students' likelihood to talk in class. This 19-item Likert scale was adapted from Willingness to Communicate scale (McCroskey, 1992). The scale involved several situations: Interest in class or topic, motivation, similarity to the rest of the students, similarity to the instructors, and seating arrangement (Menzel \& Carrell, 1999). The response categories were changed to "always," "often," "sometimes," "seldom," and "never." Sample items include "when the class is engaged in an open discussion, how likely will you talk in class?" and "when the professor asks for a response from the class, how likely will you talk in class?” The scale had high alpha reliability of .92 (Menzel \& Carrell, 1999). The current reliability in this study was .96 .

Language Competence. A scale adapted from the Self-Perceived Communication Competence scale (SPCC) (McCroskey \& McCroskey, 1988), was used to measure students' perceptions of their own ability when speaking in English. The SPCC is a 12-item scale, including four types of communication settings: Public, large group, small group, and dyad, with three types of receivers: Strangers, acquaintances, and friends. In the original scale, respondents evaluate their degree of competence from $0 \%$ (incompetent) to $100 \%$ (competent) in each setting. The scale had high reliability of .92 and good construct validity (Lu \& Hsu, 2008). In this study, only six items regarding large and small group settings were included because this study focused on class discussion. The response categories were also modified into a Likert-type scale: "Very easy," "easy," "neutral," "difficult," and "very difficult." Two words, "in English," were added to the end of each item in order to measure English competence. The current reliability in this study was .91.

Demographic Items. Participants were asked about their gender, age, nationality, major, educational status, first language, and number of months living in the United States. Participants were also asked to provide the information about the class they chose to evaluate. Class type was measured by asking whether the class is a lecture-oriented or discussionoriented class. Class size was measured by indicating an approximate number of students enrolled in class.

\section{RESULTS}

Table 1 shows all relevant means, standard deviations, and Pearson's correlations. Structural equation modeling (SEM) with maximum likelihood 
estimation, by SPSS Amos 21, was used to test all hypotheses. In order to test the direct and indirect effects of teacher confirmation, hypotheses testing was completed using three structural equation models (see Table 2). Only length of stay and class size were included as control variables because they were significantly related to classroom apprehension and willingness to talk in class (see Table 1).

Table 1. Pearson Correlation Matrix of Variables, Means, Standard Deviations, and Reliabilities

\begin{tabular}{lccccccccc} 
Variables & M & SD & 1 & 2 & 3 & 4 & 5 & 6 & alpha \\
\hline & & & & & & & & & \\
(1) TC & 67.68 & 10.76 & - & - & - & - & - & - & .93 \\
(2) CC & 66.20 & 14.72 & $.60^{* *}$ & - & - & - & - & - & .96 \\
(3) LC & 23.21 & 5.05 & $.20^{*}$ & $.29 * *$ & - & - & - & - & .91 \\
(4) CCA & 56.21 & 17.70 & $-.23^{* *}$ & $-.31^{* *}$ & $-.51^{* *}$ & - & - & - & .95 \\
(5) WTT & 63.34 & 16.49 & $.32^{* *}$ & $.34^{* *}$ & $.42^{* *}$ & $-.83^{* *}$ & - & - & .96 \\
(6) LS & 21.48 & 23.61 & .08 & $.17^{*}$ & .08 & $-.17^{*}$ & $.16^{*}$ & - & - \\
(7) CS & 34.93 & 36.14 & $-.19 *$ & $-.20^{*}$ & .06 & $.18^{*}$ & $-.22^{* *}$ & -.06 & -
\end{tabular}

Note. $* p<.05 . * * p<.01$. (1) TC $=$ Teacher Confirmation. (2) $\mathrm{CC}=$ Classroom Connectedness. (3) $\mathrm{LC}=$ Self-perceived Language Competence. (4) CCA= Classroom Apprehension. (5) WTT= Willingness to Talk in Class. (6) LS= Length of Stay (in months). (7) CS= Class Size (number of students).

Table 2. Results of Hypothesis Testing: Goodness-of-Fit Indices, Regression Coefficients, and R-Squared

\begin{tabular}{|c|c|c|c|c|c|c|c|c|}
\hline Models & Hypotheses & $\chi^{2}$ & Df & GFI & RMS & AGFI & $\beta$ & $r^{2}$ \\
\hline \multirow[t]{2}{*}{1} & $\mathrm{H} 1: \mathrm{TC} \rightarrow \mathrm{CCA}$ & 4.77 & 3 & .99 & .07 & .92 & $-.29 * *$ & .11 \\
\hline & $\mathrm{H} 2: \mathrm{TC} \rightarrow \mathrm{WTT}$ & & & & & & $.21 *$ & .07 \\
\hline \multirow[t]{5}{*}{2} & $\mathrm{H} 1: \mathrm{TC} \rightarrow \mathrm{CCA}$ & 7.77 & 5 & .98 & .07 & .91 & -.07 & .10 \\
\hline & $\mathrm{H} 2: \mathrm{TC} \rightarrow$ WTT & & & & & & .17 & .13 \\
\hline & $\mathrm{H} 3: \mathrm{CC} \rightarrow \mathrm{CCA}$ & & & & & & $-.25 * *$ & \\
\hline & $\mathrm{H} 4: \mathrm{CC} \rightarrow \mathrm{WTT}$ & & & & & & $.22 *$ & \\
\hline & $\mathrm{H} 5: \mathrm{TC} \rightarrow \mathrm{CC}$ & & & & & & $.59 * * *$ & \\
\hline \multirow[t]{8}{*}{3} & $\mathrm{H} 1: \mathrm{TC} \rightarrow \mathrm{CCA}$ & 10.77 & 8 & .98 & .05 & .92 & -.04 & .25 \\
\hline & $\mathrm{H} 2: \mathrm{TC} \rightarrow$ WTT & & & & & & .15 & .29 \\
\hline & $\mathrm{H} 3: \mathrm{CC} \rightarrow \mathrm{CCA}$ & & & & & & -.13 & \\
\hline & $\mathrm{H} 4: \mathrm{CC} \rightarrow \mathrm{WTT}$ & & & & & & .12 & \\
\hline & $\mathrm{H} 5: \mathrm{TC} \rightarrow \mathrm{CC}$ & & & & & & $.59 * * *$ & \\
\hline & $\mathrm{H} 6: \mathrm{CC} \rightarrow \mathrm{LC}$ & & & & & & $.29 * *$ & \\
\hline & $\mathrm{H} 7: \mathrm{LC} \rightarrow \mathrm{CCA}$ & & & & & & $-.45 * * *$ & \\
\hline & H8: LC $\rightarrow$ WTT & & & & & & $.36 * * *$ & \\
\hline
\end{tabular}

Note. $* \mathrm{p}<.05 . * * \mathrm{p}<.01 .^{* * *} \mathrm{p}<.001$. GFI $=$ Goodness of Fit Index; RMS = Root-Mean-Square; AGFI $=$ Adjusted Goodness of Fit Index. TC $=$ Teacher Confirmation. $\mathrm{CC}=$ Classroom

Connectedness. $\mathrm{LC}=$ Self-perceived Language Competence. $\mathrm{CCA}=$ Classroom Apprehension. WTT= Willingness to Talk in Class. 
Cultural backgrounds (individualistic vs. collectivistic nations by Hofstede's [2001] cultural index) and class types (lecture vs. discussion) were not included in the models because they did not significantly influence classroom apprehension and willingness to talk in class. In addition, the results of initial testing revealed poor fits between the specified models and the data. After allowing the correlated errors between CCA and WTT, the goodness-of fit indices, including $\chi^{2}$, GFI, RMS, and AGFI, all demonstrated good fits between the models and the data (see Table 2).

As shown in Table 2, the first SEM tested the direct effects of TC on CCA and WTT. Results indicated that teacher confirmation was negatively related to classroom apprehension (H1), and positively related to willingness to talk in class (H2). Thus, both $\mathrm{H} 1$ and $\mathrm{H} 2$ were supported. TC explained $11 \%$ and $7 \%$ of the variance in CCA and WTT, respectively.

The second SEM tested the indirect effect of TC on CCA and WTT via CC. Results indicated that classroom connectedness was negatively related to classroom apprehension (H3), and positively related to willingness to talk in class (H4). Teacher confirmation was positively related to classroom connectedness (H5). Thus, H3, H4, and $\mathrm{H} 5$ were supported. In addition, the regression coefficients from TC to CCA and WTT became insignificant after adding CC as the intervening variable. Thus, classroom connectedness mediated the relationships from teacher confirmation to classroom apprehension and willingness to talk in class among international students. A combination of TC and CC explained $10 \%$ and $13 \%$ of the variance in CCA and WTT, respectively.

The third SEM tested the indirect effects of TC via CC and subsequently LC. Classroom connectedness was positively related to selfperceived language competence (H6). Language competence was negatively related to classroom apprehension (H7) and positively related to willingness to talk in class among international students (H8). Thus, H6, H7, and H8 were supported. In addition, the regression coefficients from TC to CC and WTT were further reduced and remained insignificant, while the coefficients from CC to CCA and WTT decreased substantially and became insignificant. Thus, self-perceived language competence mediated the relationships from TC and CC to CCA and WTC. Overall international students' ratings of teacher confirmation, classroom connectedness, and self-perceived language competence explained $25 \%$ and $29 \%$ of the variance in classroom apprehension and willingness to talk in class, respectively.

\section{DISCUSSION}

This study investigated international students' perceptions of teacher behaviors, classroom environment, and class participation. The results indicated that teacher confirmation behaviors influence classroom 
apprehension and willingness to talk in class directly, as well as indirectly through classroom connectedness and self-perceived language competence. Regardless of length of stay in the U.S. and class size, the more positive relationships international students have with their teacher and classmates, the more confident they feel when speaking in English. As a result of these relationships, international students will experience less fear or anxiety, and they are more likely to express ideas or opinions in class. These findings further support WTC theory in a second language (MacIntyre et al., 1998; Clement et al., 2003) positing that students are less apprehensive and more willing to communicate in class when they experience positive intergroup climate and attitudes, and feel confident about communicating in L2. These findings also extend previous research (Sidelinger \& Booth-Butterfield, 2010) indicating that teacher confirmation helps build supportive student-tostudent relationships, which in turn, improve students' learning outcomes and class involvement.

Furthermore, self-perceived language competence appears to be the most significant factor predicting international students' classroom apprehension and willingness to talk in class. This result is consistent with the previous finding that student confidence is the major explanation for class participation (Fassinger, 2000; Neer, 1987). While previous research indicated that international students' confidence levels and class participation are influenced by their language skills and cultural backgrounds (Liu, 1997; Lu \& Hsu, 2008; Tompson \& Tompson, 1996), this study further discovered that student-to-student relationships play an important role in building international students' confidence when participating in class. When fellow students are not showing interest or support to each other's comments, international students might think negatively, such as "my ideas are not welcome," and "my accent is difficult to understand." Such negative thoughts may further increase students' communication anxiety or fear, which in turn, decreases their likelihood to speak up in class.

Previous researchers (Neer 1987; Neer \& Kircher, 1989) recommended some instructional practices for building supportive interpersonal climate and reducing classroom apprehension, such as allowing students sufficient time to offer response, promoting personal interest in discussion, avoiding producing stress, circular seating, and small group interaction. Compared to these recommendations, the findings of the current study offer practical implications targeting international students. To make international students feel more comfortable participating in class, it is important for instructors to give out assignments, hold activities, and establish norms that allow students developing strong bonds and support with each other in the classroom. International students often feel isolated from domestic students or only interact with other international students 
(Tompson \& Tompson, 1996). Small group activities or assignments that involve coordination between domestic and international students in completing a specific task may help students develop supportive relationships and create a positive communication climate in class.

In addition, class discussion tends to be dominated by a few outspoken, talkative students. Given the language and cultural constraints, it could be hard for international students to get their speaking turns and thus they remain quiet. Instructors should try to equalize speaking opportunities for students. For example, in a seminar class, instead of having an open discussion during the entire class period, each student can give a short oral report on the progress of his or her research project and the rest of the class can provide feedback afterwards. Each student can also take turns leading discussion over the assigned readings. The more opportunities international students have for participating in class, the more they feel they are parts of the class group, and the more comfortable they should feel when speaking up in class.

Several limitations need to be acknowledged in this study. First, this study was conducted in a small town where the majority of students are Caucasian Americans. The results might be different if data were collected from international students in large urban universities. To increase generalizability of these findings, a larger sample size with participants from different geographical areas should be used. Second, this study focused on international students' perceptions of teacher behaviors, classroom environment, and class participation. Given the importance of peer relationships in the classroom, future study may also investigate domestic students' attitudes toward international students, and survey instructors about effective ways to improve connectedness between international and domestic students. Third, this study did not find significant differences between students from individualistic and collectivistic cultures. Perhaps some international students choose to study in the U.S. because they identify more with American culture than their culture of origin. Future research should measure individual cultural orientation rather than classifying cultures based on nations. Fourth, this study used a cross-sectional survey research design. A longitudinal research design would allow observing the changes in participants' classroom participation over time. In addition, different data collection procedures, such as conducting interviews, observing classroom participation, or using experiments, may increase our understanding about the relationships between teacher behaviors, classroom connectedness, and classroom participation among international students in American classrooms.

In conclusion, international students bring global perspectives into U.S. classrooms and enhance the intellectual environment of domestic students. However, they often have difficulties in class participation due to 
the feeling of social isolation and low confidence in speaking English. For better idea-exchange outcomes, international students need to feel welcome and accepted not only by their teacher, but also fellow students. More research is needed to investigate ways to improve international students' connectedness with domestic students in the classroom, which should further help them to get involved in the larger academic community.

\section{REFERENCES}

Clément, R., Baker, S. C., \& MacIntyre, P. D. (2003). Willingness to communicate in a second language: The effects of context, norms, and vitality. Journal of Language and Social Psychology, 22, 190-209.

Dwyer, K. K., Bingham, S. G., Carlson, R. E., Prisbell, M., Cruz, A.M., \& Fus, D. A. (2004).Communication and connectedness in the classroom: Development of the connected classroom climate inventory. Communication Research Reports, 21, 264-272. doi: 10.1080/08824090409359988

Ellis, K. (2000). Perceived teacher confirmation. Human Communication Research, 26, 264-291.

Ellis, K. (2004). The Impact of Perceived Teacher Confirmation on Receiver Apprehension,Motivation, and Learning. Communication Education, 53, 120. doi:10.10/0363452032000135742

Fassinger, P. A. (2000). How classes influence students' participation in college classroom. Journal of Classroom Interaction, 35, 38-47.

Frisby, B. N., \& Martin, M. M. (2010). Instructor-student and student-student rapport in the classroom. Communication Education, 59, 146-164. doi: $10.1080 / 03634520903564362$

Hofestede, G. (2001). Culture's consequences: Comparing values, behaviors, institutions, organizations across nations $\left(2^{\text {nd }}\right.$ ed.). Thousand Oaks, CA: Sage.

Hsu, C-F. (2002). The influence of self-construal, family and teacher communication patternson communication apprehension among college students in Taiwan. Communication Reports, 15, 123-132. doi: 10.1080/08934210209367759

Hsu, C-F. (2007). A cross-cultural comparison of communication orientations betweenAmericans and Taiwanese. Communication Quarterly, 55, 359374. doi:10.1080/01463370701497831

Hsu, C-F. (2012). The influence of vocal qualities and confirmation of nonnative English-speaking teachers on student receiver apprehension, affective learning, and cognitive learning. Communication Education, 61, 4-16. doi: $10.1080 / 03634523.2011 .615410$

Institute of International Education. (2014). Open doors report on international educational exchange. Retrieved from http://www.iie.org/en/Research-andPublications/Open-Doors

Krejcie, R. V., \& Morgan, D. W. (1970). Determining sample size for research activities. Educational and Psychological Measurement, 30, 607-610.

Liu, L. (2007). International students' perceptions of intercultural communication 
apprehension. (Master's thesis). Retrieved from http://scholarworks.sjsu.edu/etd_theses/3425

Lu, Y., \& Hsu, C-F. (2008). Willingness to communicate in intercultural interactions betweenChinese and Americans. Journal of Intercultural Communication Research, 37, 75-88. doi: 10.1080/17475750802533356

MacIntyre, P. D. (1994). Variables underlying willingness to communicate: Causal analysis. Communication Research Reports, 11, 135-142.

MacIntyre, P. D., Babin, P. A., \& Clement, R. (1999). Willingness to communicate: Antecedents and consequences. Communication Quarterly, 47, 215-229.

MacIntyre, P. D., Baker, S. C., \& Clément, R. (2003). Willingness to communicate in a second language: the effects of context, norms, and vitality. Journal of Language and Social Psychology, 22. 190-209.

MacIntyre, P. D., Clement, R., Dornyei, Z., \& Noels, K. A. (1998). Conceptualizing willingness to communicate in a L2: A situational model of L2 confidence and affiliation. The Modern Language Journal, 82, 545-562.

McCroskey, J. C. (1977). Oral communication apprehension: A summary of recent theory and research. Human Communication Research, 4, 78-96.

McCroskey, J. C., \& McCroskey, L. L. (1988). Self-report as an approach to measuring communication competence. Communication Research Reports, 5, 108-113.

McCroskey, J. C. (1992). Reliability and validity of the willingness to communicate scale. Communication Quarterly, 40, 16-25.

McCroskey, J. C., \& Richmond, V. P. (1987). Willingness to communicate and interpersonal communication. In J. C. McCroskey \& J. A. Daly (Eds.), Personality and interpersonal communication (pp. 129-156). Beverly Hills, CA: Sage.

Menzel, K. E., \& Carrell, L. J. (1999). The impact of gender and immediacy on willingness to talk and perceived learning. Communication Education, 48, 31-40.

Myers, S. A., Zhong, M., \& Guan, S. (1998). Instructor immediacy in the Chinese college classroom. Communication Studies, 49, 240-255.

Neer, M. R. (1987). The development of an instrument to measure classroom apprehension. Communication Education, 36, 154-166.

Neer, M. R., \& Kircher, W. F. (1989). Apprehensives’ perception of classroom factors influencing their class participation. Communication Research Reports, 6, 70-77.

Organization for Economic Co-operation and Development. (2013). Education at a glance 2013: OECD indicators. Retrieved from http://dx.doi.org/10.1787/eag-2013-en

Organization for Economic Co-operation and Development. (2014). Indicator C4: Who studies abroad and where. Education at a Glance 2014: OECD Indicators. Retrieved from http:/www.oecd.org/edu/EAG2014Indicator\%20C4\%20\%28eng\%29.pdf

Sidelinger, R. J. \& Booth-Butterfield, M. (2010). Co-constructing student involvement: An examination of teacher confirmation and student-tostudent connectedness in the college classroom. Communication Education, 59, 165-184. doi: 10.1080/03634520903390867

Tompson, H. B., \& Tompson, G. H. (1996). Confronting diversity issues in the 
classroom with strategies improves satisfaction and retention of international students. Journal of Education for Business, 72, 53-57.

Zhang, Q. (2005). Immediacy, humor, power distance, and classroom communication apprehension in Chinese college classrooms. Communication Quarterly, 53, 109-124. doi:10.1080/01463370500056150

CHIA-FANG (SANDY) HSU, PhD., is an associate professor of communication and journalism. Her research interests include communication anxiety, cultural adaptation, and interpersonal relationships. She teaches research methods, nonverbal communication, and group communication. Email: hsus@uwyo.edu

I-TING (JOYCE) HUANG, MS., is a sales representative. Portions of this paper are based on her master's thesis under the first author's supervision. She presented this paper at the annual convention of the International Communication Association in London, UK, 2013. Email: alllightup@hotmail.com 